Article

\title{
Convivial Greenstreets: A Concept for Climate-Responsive Urban Design
}

\author{
Ken Tamminga ${ }^{1}$, João Cortesão ${ }^{2, *} *$ and Michiel Bakx ${ }^{2}$ (I) \\ 1 Department of Landscape Architecture, The Pennsylvania State University, University Park, PA 16802, USA; \\ krt1@psu.edu \\ 2 Landscape Architecture and Spatial Planning Group, Wageningen University, 6708 PB Wageningen, \\ The Netherlands; michiel.bakx@wur.nl \\ * Correspondence: joao.cortesao@wur.nl
}

Received: 16 March 2020; Accepted: 4 May 2020; Published: 7 May 2020

\begin{abstract}
This paper presents a conceptual framework for using "convivial greenstreets" (CG) as a resource for climate adaptation. When applied consistently, CG can become an emerging green practice with a positive impact on urban adaptation to climate change: CG may provide localized climate amelioration in ways that support social engagement outdoors. However, as spontaneous phenomena, CG should neither become an academic nor an aesthetic prescriptive tool. How then can CG be used as an active resource for urban adaptation to climate change while avoiding these two potential pitfalls? To explore this question, we present the concept of CG and the ways it can be situated in theoretical urbanism and analogous urban morphologies. We profile the CG inventory corpus and conceptualization that has taken place to date and expand them through a climate-responsive urban design lens. We then discuss how CG and climate-responsive urban design can be brought together while preventing the academization and aestheticizing of the former. This discussion is illustrated with a group of visualizations. We conclude by submitting that climate-responsive urban design and extensive and robust CG practices can co-operate to promote more resilient communities and urban climates. Finally, the conceptual framework herein sets an agenda for future research.
\end{abstract}

Keywords: conviviality; greenstreets; urban climate; climate-responsive urban design

\section{Introduction}

This paper presents a conceptual framework for using the concept of "convivial greenstreets" (CG) as an active resource for climate adaptation in urban areas. This is an exploratory study around the hypothesis that CG, when applied consistently and widely, can become an emerging green practice with impacts on the climate adaptation of urban areas. This hypothesis builds on preliminary work on the conceptualization of CG [1,2] and expands it with knowledge on climate-responsive urban design, in particular on the thermal retrofitting of outdoor public spaces in dense urban areas [3].

Anchored on previous work conducted by Tamminga [1,2], CG are herewith defined as the sum of plants, their associated accoutrements, and their supportive context that occur in dense, yardless urban cores. CG are an informal-sector phenomenon resulting from assemblages of features and patterns enacted by a variety of local actors, mostly residents, merchants, and/or employees who share a street's frontage. As an informal-sector phenomenon, in CG, local actors work as gardeners "who cultivate plants to a degree sufficient to elicit some sensory appreciation on the part of passers-by and, now and then, to prompt social engagement between cultivators, neighbours, and passers-by" [2] (p. 1128). These informal actions might take place in semi-private areas encompassed by the streetscape (e.g., facades, front stoops, or flowerbeds) or overlapped on the public streetscape. 
Our readings of the literature and on-site observations suggest that streetside horticulture in denser urban cores provides local actors opportunities to recreate and express themselves in their immediate contexts. As plants are nurtured, social interactions occur. Gardeners and passers-by exchange pleasantries; sometimes, more involved dialogue ensues, and relationships are strengthened. Early adopters tend to influence their neighbors positively in contributing to their CG. The more robust CG contribute to a visually impactful and animated character to the streetscape and promote a sense of identity. While quantitative inquiries are in progress, we expect that $C G$ will be found to be productive in other ways. For instance, pollinators are certainly active on the CG we have investigated, and many CG gardeners were observed growing potted vegetables and espaliered fruit-bearing vines. At the scale of the metropolis, CG may offer a model for how compact urban form and residential development may be structured, with the street as a desirably convivial urban design component. CG may thus contribute to the slate of approaches that offer antidotes to unsustainable urban sprawl.

In the context of climate-responsive urban design, CG can be of importance because: they occur mainly where solutions countering urban heat are most needed, i.e., dense, yardless urban cores; they are applied over the whole streetscape; and they deal with spatial elements frequently used in climate-responsive urban design. Not incidentally, if CG can provide localized climate amelioration, they do it in ways that support social engagement outdoors. There is, therefore, potential in exploring the concept of CG as a green urban development tool/practice. This concept is of importance as it combines evidence-based knowledge on climate-responsive design with informal practices, both largely employing green elements. The greening of cities may play a vital role in fostering social cohesion. Both aspects, climate adaptation and social cohesion, are paramount for more resilient urban societies.

However, as spontaneous phenomena, CG should neither become an academic, nor an aesthetic prescriptive tool. How can then CG be used as an active resource for urban adaptation to climate change while avoiding these two potential pitfalls? This paper addresses this question. By doing so, our aim is to propose a conceptual framework setting an agenda for future research on the use of CG as a concept for climate-responsive urban design; a framework assigning a climate-regulation role to CG while securing their informal character.

To explore the question above, firstly, in the Materials and Methods section, we present how we define the concept of CG and how we situate it in theoretical urbanism and analogous urban morphologies. We profile the CG inventory corpus and conceptualization that have taken place to date and expand them through a climate-responsive urban design lens. In the Results section, we elaborate on the reciprocity found between CG and climate-responsive urban design, based on the comparison of theories, concepts, and elements presented in the Materials and Methods. Afterwards, in the Discussion section, we discuss how this reciprocity can be secured while preventing the academization and aestheticizing of CG practices. This discussion is illustrated with a group of visualizations synthesizing the intrinsic spontaneity, vitality, and inclusiveness of CG and their role in climate-adaptation. In the Conclusion, we submit that the cooperation between climate-responsive urban design and more extensive and robust CG practices can be a powerful way of prompting resilient urban climates.

\section{Materials and Methods}

In this section, we present the concept of CG and their types and the fundamentals of climate-responsive urban design. We look into the two groups of information in order to explore the reciprocity between CG and climate-responsive urban design. In the Results section, we compare the theories, concepts, and typical spatial elements presented below, critically looking at previous studies. 


\subsection{The Concept of Convivial Greenstreets and its Types}

Earlier efforts by Tamminga [1] aligned the definition of CG presented above with relevant theory in urbanism and related social and physical sciences. A concept map developed in Tamminga [2] noted that the CG concept:

- is informed by theory in urban ethnography, urbanism, urban morphology, landscape architecture and urban design, urban planning, architectural theory and criticism, environmental psychology, urban ecology, phenomenology, structuralism, and semiotics;

- can be classified according to urban contexts;

- can be deconstructed as a taxonomy;

- $\quad$ is spatially interstitial;

- is socially liminal;

- shows functional variation in botany; and

- $\quad$ engages the science of ecosystem services.

A fundamental task in establishing the CG concept is affirming its range of physical and spatial forms. To this end, an inventory of CG across European cities was carried out. The choice of cities started with locations having a tradition of urban horticulture, primarily in The Netherlands, the Ruhr valley in Germany, and Belgium. Professionals operating in Western Europe gave advice on the preliminary list of cities, which led to the list's expansion. A critical shortlist based on the on-site reconnaissance described below followed. Eventually, the inventory comprised 31 cities across 13 European countries (Table 1).

Table 1. Countries and cities included in the inventory of convivial greenstreets.

\begin{tabular}{cc}
\hline Country & Cities \\
\hline Belgium & Brussels, Ghent \\
\hline Czech Republic & Prague, Karlštejn \\
\hline Denmark & Copenhagen \\
\hline France & Paris \\
\hline Germany & Cologne, Bonn, Frankford, Aachen, Andernach, Rostock \\
\hline Hungary & Budapest, Szentendre \\
\hline Iceland & Reykjavik \\
\hline Ireland & Dublin, Limerick, Galway \\
\hline Portugal & Lisbon, Cascais, Sintra \\
\hline Scotland & Edinburgh, Dundee \\
\hline Spain & Barcelona \\
\hline Sweden & Lund \\
\hline The Netherlands & Amsterdam, Rotterdam, Leiden, Delft, Leeuwarden, Katwijk \\
\hline
\end{tabular}

These cities were taken as a starting point for the typological framework below (Table 2). However, because CG are a worldwide phenomenon, the framework was meant to be generalizable to built-up cores beyond Europe. Next, urban analytical and ethnographic approaches described in Kusenbach [4], Tilley [5], Nuvolati [6], and Ramsden [7] were used to inform the inventory process. Google Maps aerial photography and Google StreetView (GSV) were used to assess likely urban densities and streetscape characteristics, respectively. GSV panoramic images provided initial remote indicators of streetside horticulture activity. This set the target neighborhoods. 
Table 2. Typological framework of convivial greenstreets. Adapted from Tamminga [2].

\begin{tabular}{|c|c|c|c|c|}
\hline CG Types & CG Sub-Type & Adjacent Land Use & $\begin{array}{l}\text { Height/Width Ratio; } \\
\text { \# of Stories }\end{array}$ & $\begin{array}{l}\text { Key Interacting } \\
\text { Agents/Actors }\end{array}$ \\
\hline \multirow{2}{*}{ 1. Residential } & $\begin{array}{l}\text { 1a. } \\
\text { Residential }\end{array}$ & - entirely residential & $\begin{array}{l}\text { - } 2: 1-1: 2 \\
\text { - } 2-4 \text { stories }\end{array}$ & $\begin{array}{l}\text { - resident-resident } \\
\text { - resident-passers-by }\end{array}$ \\
\hline & $\begin{array}{l}\text { 1b. } \\
\text { Mainly residential }\end{array}$ & $\begin{array}{l}\text { - } \text { mostly residential } \\
\text { - some small commercial } \\
\text { and institutional }\end{array}$ & $\begin{array}{l}\text { - } 2: 1-1: 2 \\
\text { - } 2.5-4 \text { stories }\end{array}$ & $\begin{array}{l}\text { - resident-resident } \\
\text { - resident-merchant } \\
\text { - resident-passers-by }\end{array}$ \\
\hline \multirow{2}{*}{$\begin{array}{l}\text { 2. Mixed- } \\
\text { commercial }\end{array}$} & $\begin{array}{l}\text { 2a. } \\
\text { Mixed } \\
\text { Commercial/ } \\
\text { small-scale }\end{array}$ & $\begin{array}{l}\text { - small-scale commercial } \\
\text { - interspersed residential }\end{array}$ & $\begin{array}{l}\text { - } 2: 1-1: 3 \\
\text { - } 3-5 \text { stories }\end{array}$ & $\begin{array}{l}\text { - merchant-passers-by } \\
\text { - merchant-resident } \\
\text { - passers-by-passers-by }\end{array}$ \\
\hline & $\begin{array}{l}\text { 2b. } \\
\text { Mixed } \\
\text { commercial/larger } \\
\text { scale }\end{array}$ & $\begin{array}{l}\text { - larger scale commercial } \\
\text { and institutional }\end{array}$ & - varies & $\begin{array}{l}\text { - passers-by-passers-by } \\
\text { - employee-passers-by }\end{array}$ \\
\hline \multicolumn{2}{|l|}{ 3. Waterway } & $\begin{array}{l}\text { canals and other small } \\
\text { urban waterways lined by } \\
\text { mixed use }\end{array}$ & $\begin{array}{l}\text { - varies } \\
\text { - } 1: 1-1: 6 \\
\text { - } 2-5 \text { stories }\end{array}$ & $\begin{array}{l}\text { - waterway dwellers } \\
\text {-merchants-residents } \\
\text {-passers-by }\end{array}$ \\
\hline \multicolumn{2}{|c|}{ 4. Celebratory and Artistic } & - varies & - varies & $\begin{array}{l}\text { - varies: artists/designers- } \\
\text { participants/celebrants } \\
\text {-passers-by }\end{array}$ \\
\hline
\end{tabular}

On-site reconnaissance was conducted during growing seasons between 2011 and 2019. Target neighborhoods were crisscrossed by foot to identify and select streets that showed notable CG activity. The selected streets were then thoroughly inventoried. Plants and related paraphernalia were photographed, and field notes were taken to document street and streetscape characteristics, including building height-to-street width ratios, civic streetscape features, sidewalk conditions, adjacent land use, and related phenomena. Social interactions that appeared linked to streetside horticulture were also noted. Photo-documentation was the primary data used to devise our typological framework. Table 2 summarizes CG patterns identified to date, as herein expanded to include convivial waterways and updated to reflect evolving CG practices.

\subsubsection{Type 1. Residential}

Type 1 encompassed more diversity of gardening practice, materiality, and motives than the other types. Plantings and related accoutrements were often personalized. Most plants were common ornamentals, but edibles and plants for didactic or symbolic purposes were also present. While plants served as foundational elements of conviviality, amenities such as benches and railings and a wide range of complementary decorations and crafts contributed to streetscape personality.

As the name implies, residents played the role of cultivators or, in the case of retained ruderal plants, conservators. Relational patterns could be quite complex. Cultivators may interact with other cultivators along that segment of street; passers-by may engage plants alone or with other passers-by; and cultivators and passers-by may engage with each other and the plants being tended. Two sub-types were identified: $1 \mathrm{a}$. residential, and $1 \mathrm{~b}$. mainly residential.

Type 1 CG as a social phenomenon are not yet fully understood. Tamminga [2] (p. 1134) wrote, “... certain residential streets exhibit much more horticultural activity than others, and certain neighbourhoods accommodate a higher density of greenstreets than others." It may be that horticulturally-inclined cultural groups tend to live in close proximity; or it is possible that some 
streets harbor one or several trend-setting gardener-activists, after which "communities of practice" develop [8].

\subsubsection{Sub-Type 1a. Residential}

Sub-type 1a (Figure 1) captured the essential attributes of the most persistent CG encountered. With an intimate-scale street cross-section, limited auto traffic, and generally contiguous medium-residential land use, residents found ways of establishing plant collections in the tightest of spaces.

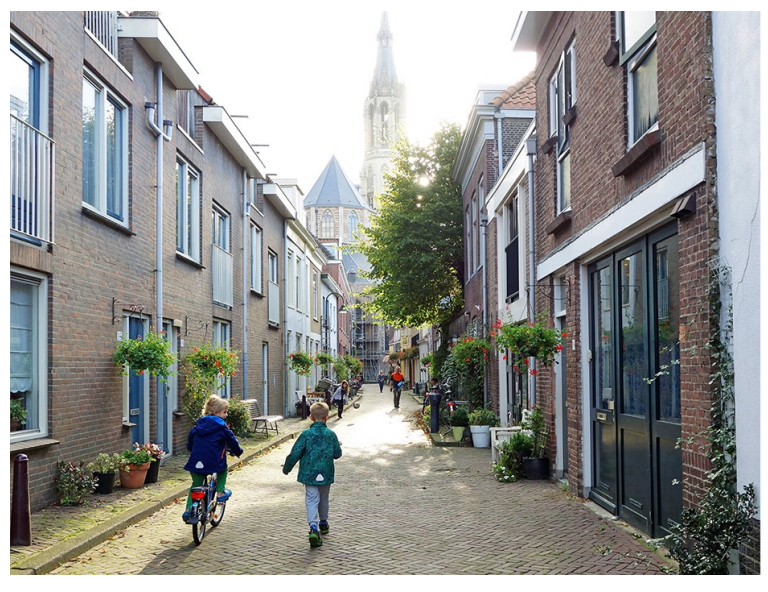

(a)

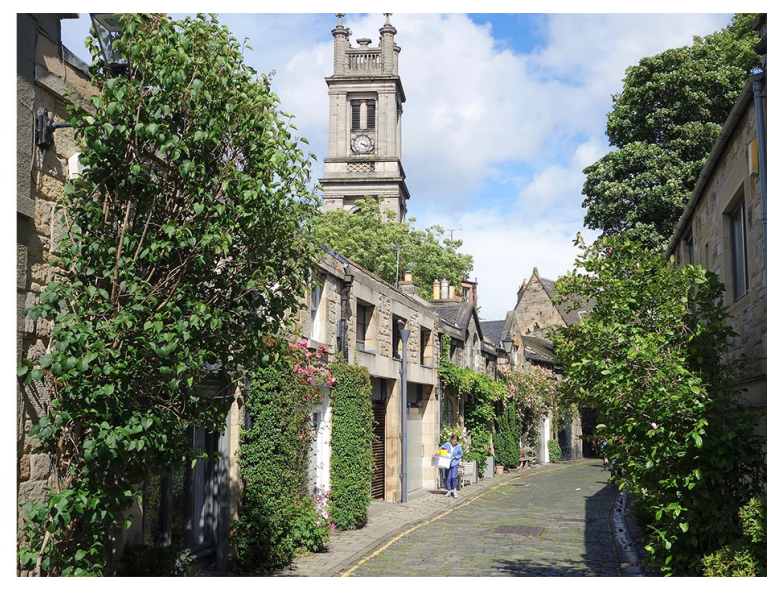

(b)

Figure 1. Illustration of Sub-type 1a. residential (a: Delft, The Netherlands; b: Edinburgh, Scotland).

\subsubsection{Sub-Type 1b. Mainly Residential}

Sub-type $1 \mathrm{~b}$ (Figure 2), while still mostly residential in nature, included small-scale commercial (e.g., bakery) or institutional (e.g., day-care center) uses. With these present, the range of interacting actors increased and additional motives (e.g., profit or institutional identity) became more likely. However, generally, the every-day functions and engagements along Sub-type $1 \mathrm{~b}$ CG remained idiosyncratic, human-scale, and interwoven into the rhythms of local domestic life.

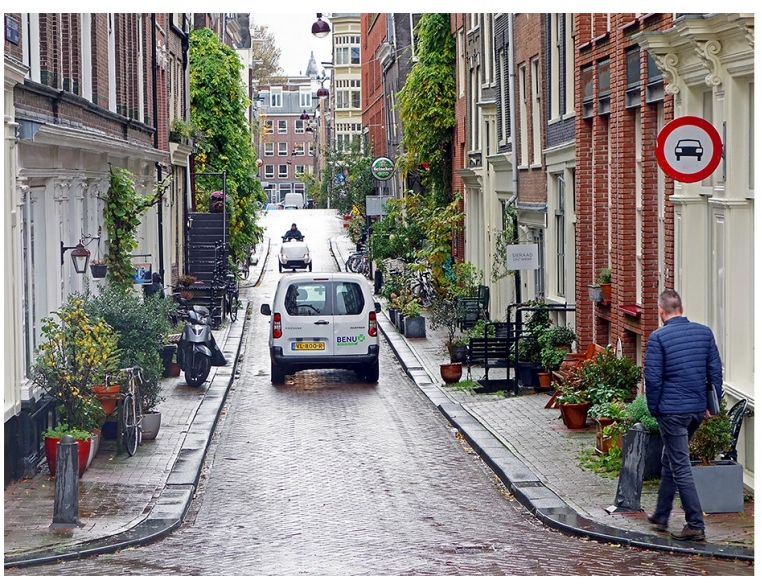

(a)

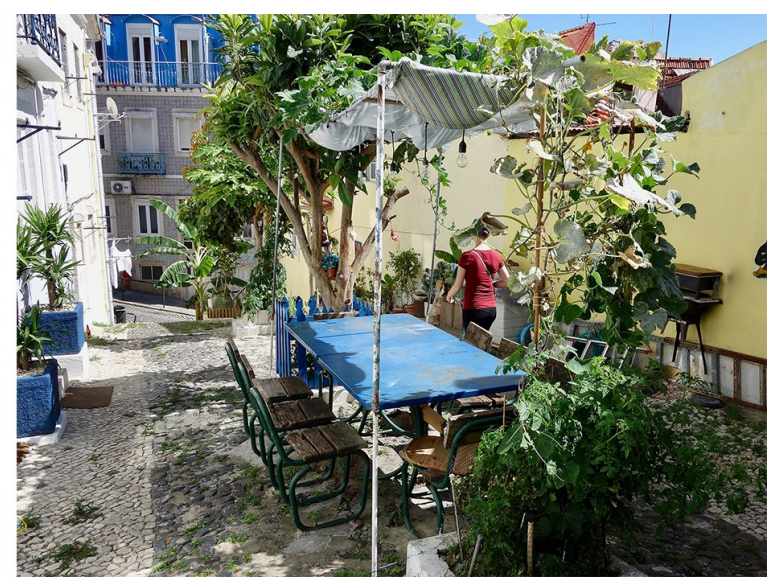

(b)

Figure 2. Illustration of Sub-type 1b. mainly residential (a: Amsterdam, The Netherlands; b: Lisbon, Portugal). 


\subsubsection{Type 2. Mixed Commercial}

Type 2 CG were associated with mixed commercial street frontages, often interspersed with residential accommodation in the upper floors. The street cross-section was more spacious, and the impact of the cars along these collector and arterial roads was more strongly felt. Two sub-types were identified: 2a. mixed commercial/small-scale and $2 \mathrm{~b}$. mixed commercial/larger scale.

\subsubsection{Sub-Type 2a. Mixed Commercial/Small-Scale}

Sub-type 2a (Figure 3) possessed some of the same horticultural and infrastructural trappings as Sub-types $1 \mathrm{a}$ and $1 \mathrm{~b}$, but fell short in some of the four essential attributes discussed above. They lacked persistent and convivial inhabitation, authorship, mixed cultures, and cues to personalized care that were the hallmarks of Sub-types $1 \mathrm{a}$ and $1 \mathrm{~b}$.

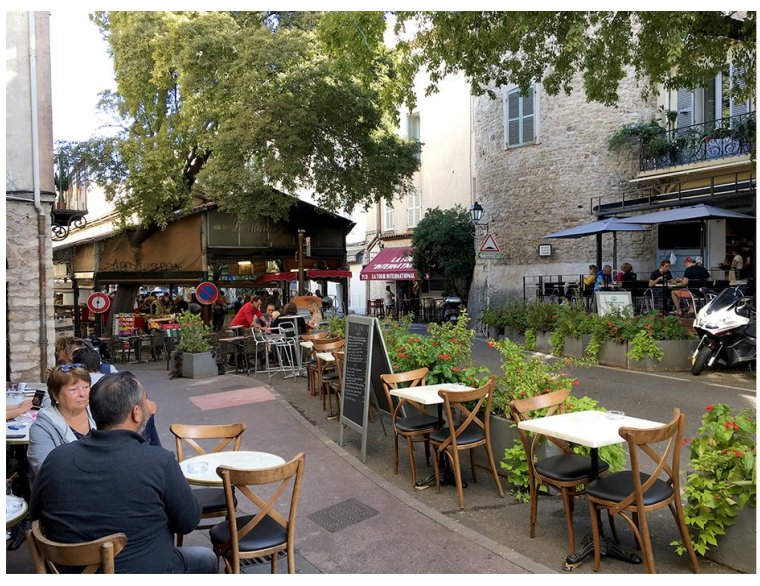

(a)

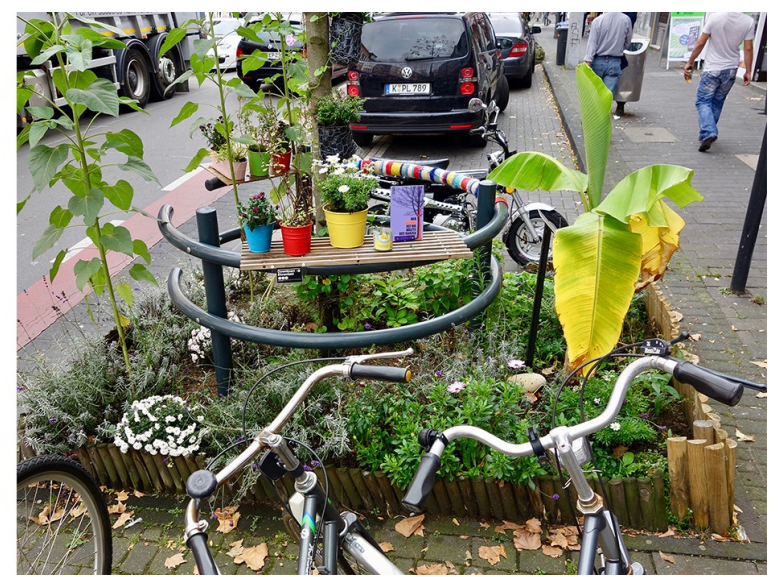

(b)

Figure 3. Illustration of Sub-type 2a. mixed commercial/small-scale (a: Antibes, France; b: Cologne, Germany).

Both Sub-type $2 \mathrm{a}$ and $2 \mathrm{~b}$ streetscapes tended to have more generous sidewalks than Type $1 \mathrm{CG}$, but Sub-type 2a presented more fine-grained mixed uses. Sub-type 2a also afforded more streetside gardening opportunities than Sub-type $2 \mathrm{~b}$ through public streetscape tree bump-outs and other remnant unpaved patches. In these situations, merchants and sometimes upper-floor residents found space to install plants, benches, and the like as overlays to the public domain. As with Type 1 CG, personalized decoration or handmade signage were sometimes incorporated, offering a one-of-a-kind bouquet, of sorts, along the otherwise generic streetscape. In several of the larger cities investigated, municipalities provided programmatic support such as compost and subsidized plant purchases.

\subsubsection{Sub-Type 2b. Mixed Commercial/Larger Scale}

Sub-type $2 \mathrm{~b}$ (Figure 4) had boulevard-scale cross-sectional dimensions, higher traffic volumes, and the associated impacts on the pedestrian experience and localized greenery. Commonly, installations were associated with hotels and large restaurants, where municipally-permitted green screening attempted to carve out some human-scale respite from traffic commotion. Tamminga [2] (p.1136) wrote, "An aura of corporatist control can permeate Type $2 \mathrm{~b}$ environs, although clients and passers-by alike seem to tolerate the lack of colloquial charm while they appreciate the shade, screening and sensory qualities afforded by the plant assemblages." In terms of daily cadence, Sub-type 2b CG were mostly active during business hours and on weekend evenings. 


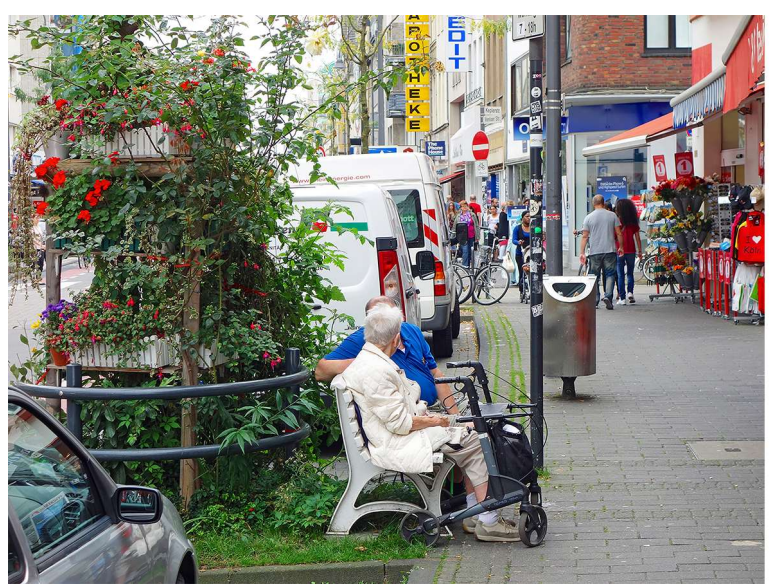

(a)

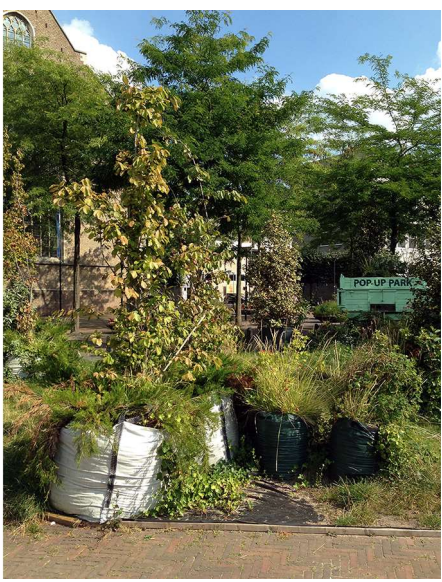

(b)

Figure 4. Illustration of Sub-type 2b. mixed commercial/larger scale (a: Cologne, Germany; b: Rotterdam, The Netherlands).

\subsubsection{Type 3. Waterway}

Type 3 (Figure 5) was a CG form unique to cities with waterways and urbanized riverfronts. They reached their most expressive form along the archetypal Dutch and Belgian city canals. Inhabitation, commerce, and intensive private- and public-sector gardening (both riparian and afloat) contributed to the convivial daily rhythms of life along these nautical streets. The availability of fresh water and the moderated microclimate readily supported plant collections on boats and canal platforms and at interstitial spaces along catwalks and bulkhead walls.

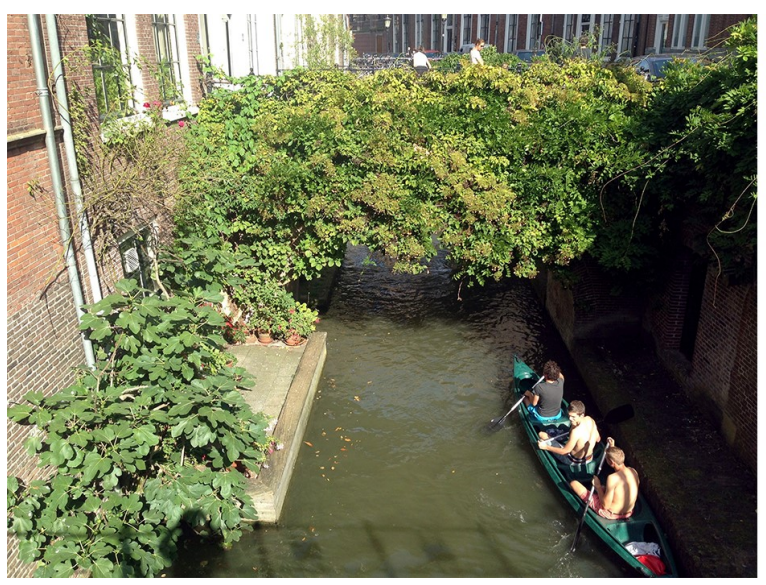

(a)

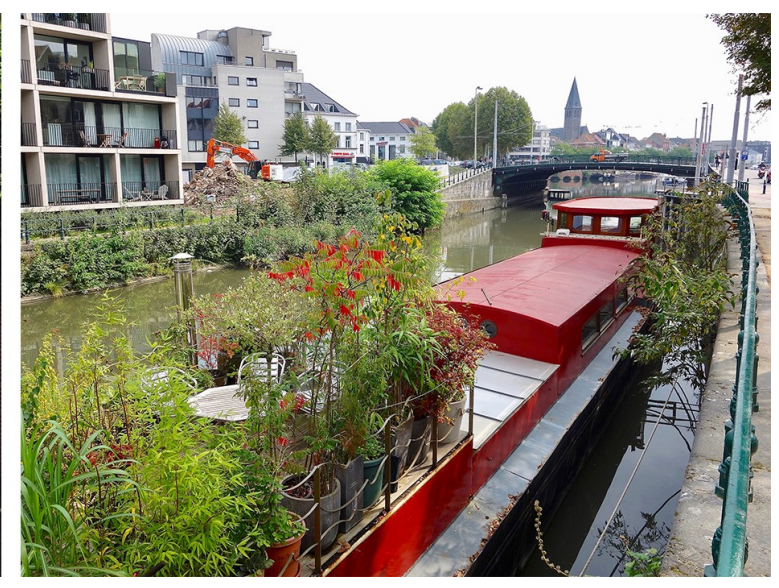

(b)

Figure 5. Illustration of Type 3. waterway (a: Utrecht, The Netherlands; b: Ghent, Belgium).

\subsubsection{Type 4. Celebratory and Artistic}

This type included streets that were convivial and green in transient ways associated with events, festivals, and rituals. Type 4 CG related by definition to temporary green installations and may occur along any type of street or public gathering space in the dense urban core. An increasingly popular example is the parklet. Spaces, from streets to squares, become temporarily animated through horticultural or green infrastructure installations initiated by urban sub- and counter-cultures looking for public expression. As a type, a wide variety of programmatic purposes were accommodated, ranging from political to romantic, to simply playful.

Figure 6 shows examples of such programs. On the left, for example, the ephemeral installation "Basil Flowers", designed by the Portuguese studio FAHR 021.3, conceptualized the hanging gardens 
and basil sale kiosks typical of São João's festivities, a hallmark of conviviality in the city of Porto, Portugal. Passers-by were engaged in emotional (residents) and sensory (residents and non-residents) ways through a blanket of basil rising in the public space.

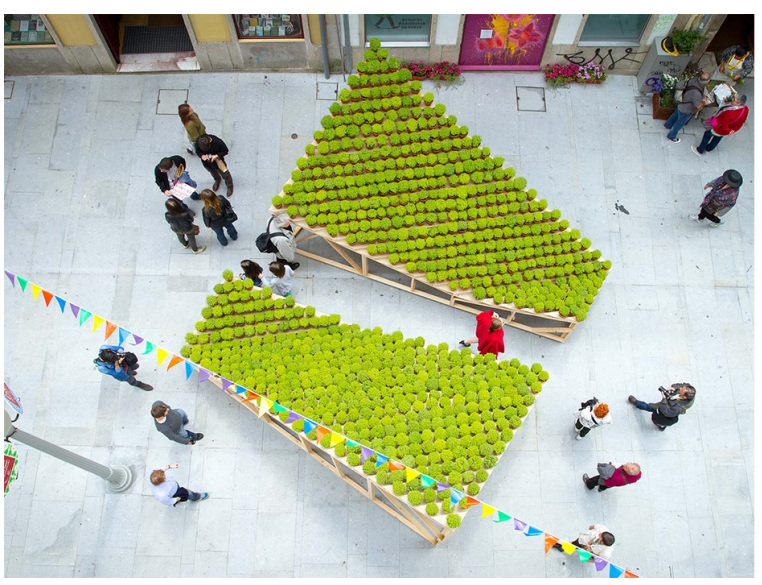

(a)

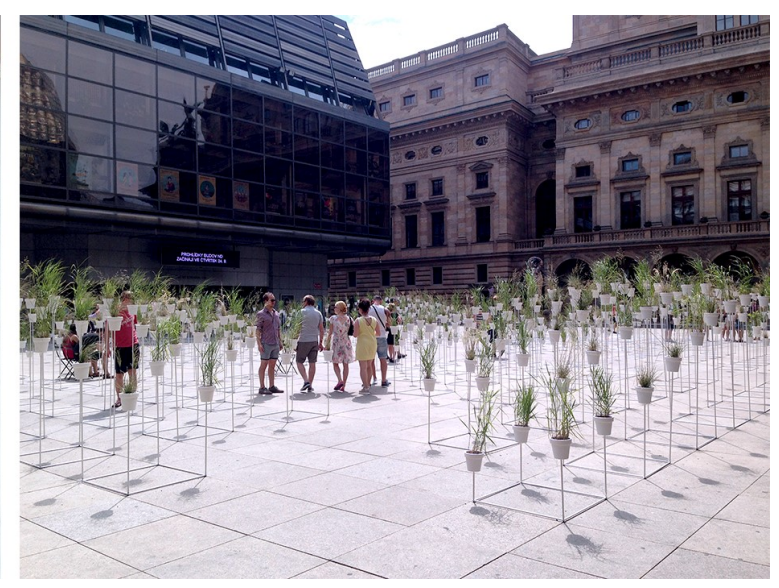

(b)

Figure 6. Illustration of Type 4. celebratory and artistic (a: Porto, Portugal, courtesy of studio FAHR.021.3; b: Prague, Czech Republic).

\subsection{Climate-Responsive Urban Design}

Climate-responsive urban design is a discipline focused on mediating site, climate, and people by combining spatial elements in a way that provides protection from negative and exposure to positive aspects of climate [9]. Climate-responsive design keeps the full picture of microclimatic effects over summer and winter in mind. However, it often focusses on countering urban heat build-up during summer periods. The reason is the many impacts of heat on urban areas, from health and mortality to infrastructure [10,11].

Amongst these impacts, urban heat can compromise the livability of outdoor spaces and, thus, significantly condition conviviality. The decision to go to and stay at an outdoor urban space largely depends on the "level of satisfaction or dissatisfaction under the prevailing climatic conditions" [12] (p. 318). When the conditions offered for thermal comfort are scarce or absent, people will avoid using an outdoor public space [13]. Creating a variety of sunny, shady, sheltered, and exposed sub-spaces yields the potential to increase the usage of outdoor public spaces throughout the year [14]. In this context, climate-responsive urban design basically seeks to:

- control the amount of solar radiation reaching a space, by providing different gradients of sun and shade;

- control exposure to wind, by providing wind sheltering in winter or stimulating cooling by ventilation in summer;

- balance air temperature and relative humidity, by bringing together parameters such as vaporization, evapotranspiration, and wind;

- enable evaporative cooling, by increasing evapotranspiration from plants and water vaporization;

- enable heat losses from surfaces, by reflecting as much solar irradiation as possible and releasing any heat stored in the materials.

There are four main categories of spatial elements commonly used to address these goals: vegetation, shading devices, materials, and water. These are primordially brought together by reference to a space's orientation and height-to-width ratio [15]. It is paramount to understand how relevant these categories are for a specific location. More than the spatial elements selected to work with, it is often their relations and interdependencies at the urban microclimatic scale that lead to the aimed 
goals. An urban microclimate can be described as the climate of small confined, well-defined spaces where the meteorological elements are mainly conditioned by immediate surrounding factors $[3,16]$. The microclimatic characteristics and thermal comfort requirements of urban outdoor spaces vary from city to city and even within the same city. Hence, climate-responsive design is a site-specific discipline often dealing with local effects.

It is also important to mention that climate-responsive elements are brought together to comply with both microclimatic and common urban design parameters such as aesthetic appeal, good detailing, accessibility, or costs. This is because design measures need to be feasible in practice and because comfort involves other dimensions beyond thermal perception [17]. In climate-responsive design, common spatial elements are simply weighed through a different (climatic) lens. We will now look into the four categories of climate-responsive design elements in more detail.

\subsubsection{Vegetation}

Trees, edges, grasses, potted plants, climbing plants, vegetated pergolas, private gardens, public gardens, parks, or lined-up urban trees are just a few of the countless ways in which vegetation can be found in urban areas. Green infrastructure, i.e., the network of urban green spaces and greenery associated with streets and built form, is an "effective adaptive strategy to limit urban heat and thermal discomfort" [18] (p. 88). Reis and Lopes [19] found in a study in Lisbon that a green area of $50 \mathrm{~m}^{2}$ could reduce air temperature by $1^{\circ} \mathrm{C}$, the reason why the authors suggested this area as the minimal size required for green spaces to improve urban microclimates significantly.

Trees are particularly important here. Through evapotranspiration, trees can lower surrounding air temperatures by as much as $5^{\circ} \mathrm{C}$ [20]. By shading, trees can substantially reduce the amount of direct solar radiation reaching outdoor ground surfaces and buildings' facades [21,22]. This influences air temperature, humidity, mean radiant temperature, and longwave radiation. Trees can also help control wind speed and direction [3,9].

Accepting spontaneous vegetation, retaining pre-existing mature specimens as much as possible, and using native species are usually good practices as these exempt supplementary irrigation and/or fertilization and because a complex vegetal ensemble is more resilient than those with less diversity [23].

\subsubsection{Shading Devices}

Man-made shading devices such as parasols, canopies, pergolas, panels, or hedges are shading solutions providing localized shade. Moveable devices have the advantage of being adjustable to particular comfort needs. This fosters thermal adaptation, i.e., "all the processes which people go through to improve the fit between the environment and their requirements" [24] (p. 96).

These devices can be used for shading whenever trees are not suitable for a space. However, green elements are usually preferable [25]. The reasons are that, in contrast with inorganic bodies, vegetation: can absorb direct solar radiation without increasing surface temperatures [26]; entails psychological benefits linked to a sense of connection with nature [27]; possesses unique aesthetic qualities and can influence people's thermal comfort perception [18]; and, trees in particular, contributes to other urban functions such as urban ecosystems, stormwater management, air quality, or urban biodiversity [28,29]. It follows that artificial man-made shading devices should be used as a "Plan b" when, for example, underground or aerial infrastructure does not allow planting.

\subsubsection{Materials}

Beyond all aesthetic considerations, surface materials can influence urban microclimates basically (but not exclusively) through their optical and moisture-related properties.

The optical properties relate to albedo and emissivity. Albedo describes the ratio between the incident and reflected solar radiation by a surface. It therefore acts as "the primary heat storage source", directly influencing the urban heat island intensity [30] (p. 6). Albedo is tightly related to colors. $\mathrm{Cool} /$ light colors are associated with high albedo values and, thus, high reflection of solar radiation; 
warm/dark colors to lower albedos and, thus, to a higher absorption of solar radiation [31]. Emissivity largely determines the long-wave radiation emitted by a surface. High-emissivity materials exposed to sun usually maintain a lower surface temperature during the day [30,32]. Several studies advocate that the combination of high albedo and emissivity values can keep urban surfaces cooler during the day $[30,33,34]$. Night-time long-wave radiation can be reduced by these means. However, in order not to hinder daytime thermal comfort, the use of high albedo and emissivity materials should be weighed by consideration of other microclimatic variables such as wind flow or shade. While wind flow has the potential to carry heat away from the street canyon, shade reduces the amount of direct solar radiation that reaches urban surfaces and, thereby, makes the albedo and emissivity of these surfaces less important variables.

Moisture-related properties deal mainly with permeability to water. There seems to be a growing awareness that the changes to soil use caused by urbanization processes lead to increased temperatures within urban areas and that, in this context, the significant amount of impermeable urban surfaces is one of the main underlying factors of urban heat islands [19,35]. As a reaction, the use of permeable pavements or depaving, i.e., removing impermeable pavers, is an increasingly popular practice. Both trends deal with restoring, at least to some extent, the cooling effects of evapotranspiration lost with the artificialization of urban surfaces. Permeable ground surfaces enable evaporative heat losses. Fundamentally, "evaporation makes the temperature of bare soil much lower than that of covered surfaces, especially asphalt, throughout the day and at night" [36] (p. 57). Previous research showed significant differences for mean radiant temperature between permeable and impermeable ground surfaces [3,12,37]. Permeable ground surfaces are also often used to store storm water and reduce runoff within the built environment [38].

Interestingly, research on material engineering has been developing new possibilities breaking through properties typically associated with building materials [3]. "Smart materials" and "smart technologies" bring possibilities to architecture, urban design, and landscape architecture that go beyond, for instance, the association of albedo with color.

\subsubsection{Water}

Water is a popular element in urban design in landscape architecture [39], frequently used for aesthetic and recreational purposes. Water can be employed through water features (e.g., fountains, cascades, water sprays) or water bodies (e.g., ponds, canals). While it has been assumed that water can lead to cooling effects, recent research on large and small urban water bodies suggested otherwise [40-42]. This new body of research indicated that water per se does not necessarily cool down its surroundings, but that its combination with shade from trees, proper ventilation, and water vaporization (e.g., water sprays) may [41].

\section{Results}

\subsection{The Core Reciprocity}

This section presents the findings from the comparison of the theories, concepts, and spatial elements presented in the previous section. In this preliminary exploration on the topic, we observed that the reciprocity between CG and climate-responsive urban design comprehended two core aspects: CG are applied over the whole streetscape; and CG deal with spatial elements frequently used in climate-responsive urban design.

\subsubsection{Convivial Greenstreets are Applied over the Whole Streetscape}

The concept of CG addresses a street as an entire spatial volume made up of the streetscape, entryways, stoops, facades, balconies, windows, alcoves, railings, and other parts. CG establish, therefore, interesting links between spatial design (as in the space between buildings) and architecture (as in buildings). Here, ground surfaces and buildings' facades are regarded as one object of design 
intervention. This relates to the concept of "climatic skin of the urban spaces" [43], i.e., the ensemble of all surfaces of a public space, buildings' facades, and pavements, that works as a continuous outdoor surface where climate-responsive design measures can be applied. This concept is of interest as improving an urban microclimate, ideally, requires thinking synergistically about the different spatial elements implemented on the ground surface and the buildings' facades surrounding it.

Ground surfaces account for a good part of total urban surfaces. For instance, in the United States, it is estimated that pavement area fractions can go up to $44 \%$ [44,45]. Furthermore, it is on this surface that most urbanized life takes place and where a good part of infrastructure can be found. Ground surfaces are also the main stage of intervention of urban design and landscape architecture. The role of ground surfaces on tackling urban climate issues and improving outdoor thermal comfort is, thus, straightforward.

Buildings' facades have important influences on urban microclimates. Together with the size of the facade and its orientation, facing materials have the most relevant influence as they determine the amount of thermal energy stored and released by facades. The thermal influence of facades on a microclimate can be mostly felt on mean radiant temperature [9]. The influence of cladding materials on the energy budget of an outdoor pace is more intense for high height-to-width ratios, i.e., narrow spaces, because as facades are closer, long-wave radiation is held longer within the space. Consequently, the street canyon will cool down more slowly [46]. Furthermore, there are architectonic elements at the indoor-outdoor interface that can influence urban microclimates, such as galleries, colonnades, or arcades, at the pedestrian level, or elements fixed onto facades above the pedestrian level, such as balconies, overhangs, trellises, or canopies. These elements can provide protection from excessive solar radiation, supplementing shading strategies at the street level [47].

Bringing these ideas together with the fact that CG basically involve anything that "might accommodate plants and related infrastructure" [2] (p. 6) suggests the potential of CG in influencing improving urban microclimates through holistic interventions in the streetscape.

\subsubsection{Convivial Greenstreets Deal with Spatial Elements Frequently Used in Climate-Responsive Urban Design}

The common spatial elements CG incorporate match those commonly used in climate-responsive urban design, when it comes to its overarching goals: to control the amount of solar radiation and wind exposure, to balance air temperature and relative humidity, and to enable evaporative cooling and heat losses from surfaces. This does not mean that one and another entirely match or follow the same reasoning. It simply recognizes similitudes that shed light on the potential that CG hold to become an emerging green practice with an impact on urban adaptation to climate change.

Figure 7 lists the CG elements inventoried to date. From the four abovementioned categories of spatial elements commonly used to address the goals of climate-responsive urban design (vegetation, shading devices, materials, and water), three are largely present in CG:

- Vegetation, represented by elements such as potted plants, wall mini-gardens, rain gardens, temporary green elements, trellised trees and vines, greenwalls, green shelves; or by actions such as interstitial planting or planting in street tree root zones.

- Shading devices, represented by elements such as awnings, sunshades, and all sorts of canopies.

- Materials, represented by elements such as cladding materials, permeable/impermeable pavers; or by actions such as depaving or painting facades in a different color. 


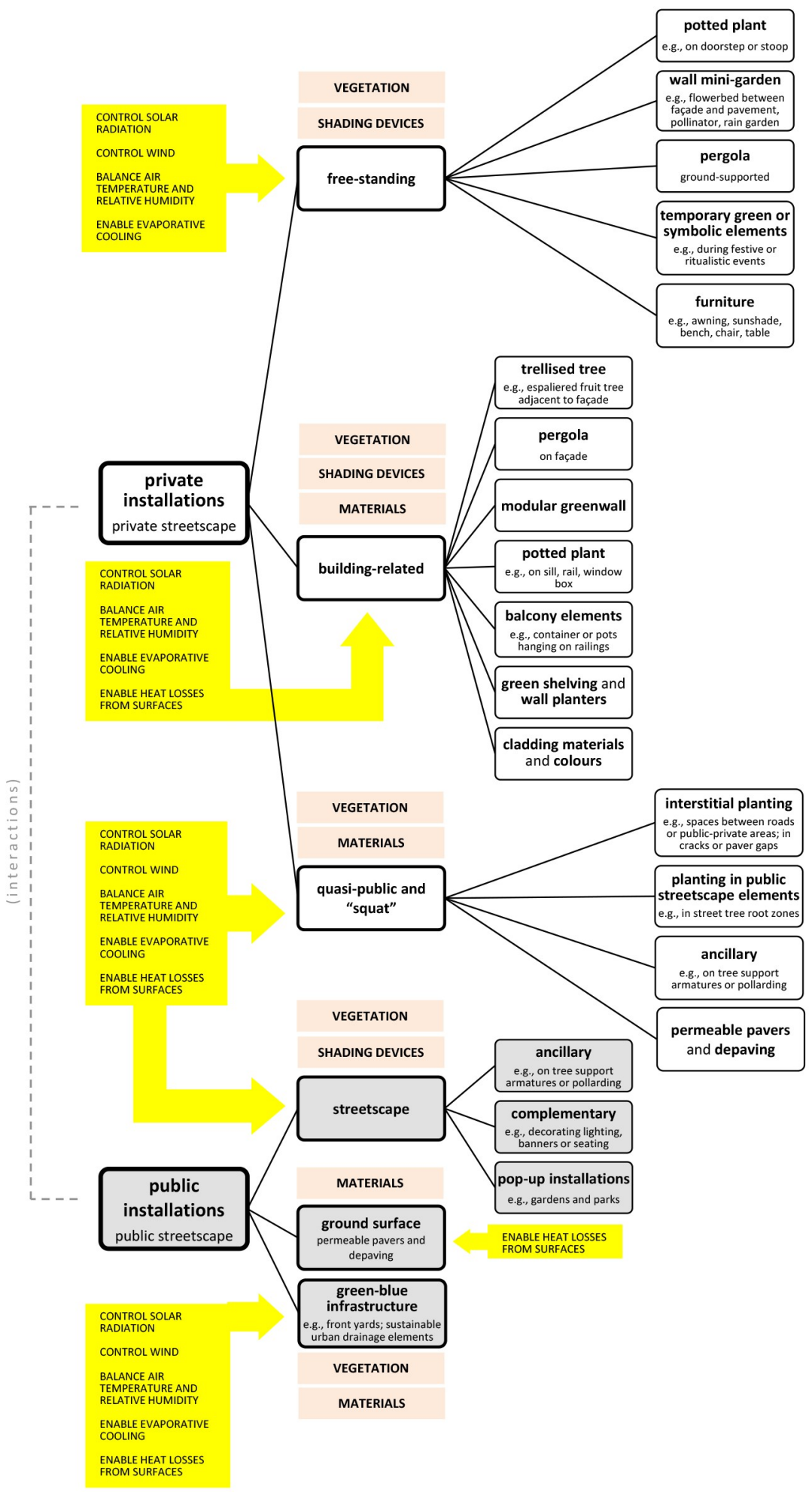

Figure 7. Hierarchical synopsis of convivial greenstreets elements (white and grey boxes) and their reciprocity with categories of common climate-responsive urban design elements ( $\tan$ boxes) and goals (yellow boxes).

In CG, all these elements (and others not herewith listed) can be found on both ground surfaces and buildings' facades. At the same time, these are elements commonly employed in climate-responsive urban design, in an array of ways, to address its (micro) climate-regulation goals. 


\subsubsection{An Integrated View}

To the end of offering an integrated view on the two core aspects of the reciprocity mentioned above, we refer to Figure 7. This figure offers a visual conceptualization of this reciprocity. The information presented in this figure is threefold: firstly, it updates the hierarchical synopsis of CG elements previously presented by Tamminga [1] with new elements and a re-arranged clustering of elements; secondly, it adds to this synopsis the climate-responsive design elements listed above, indicating to which category of CG elements they refer to; finally, it presents the climate-responsive urban design goals to which the different elements can lead.

The first aspect of note in Figure 7 is the two main spheres of action in creating CG: private installations (white boxes), describing elements that are mainly applied by local residents, shopkeepers, and employees over private components of the streetscape such as facades, front stoops, or planted soil openings near facades; and public installations (grey boxes), which may include the first group, but expand it to the city scale, mostly taking place in public components of the streetscape. Both spheres interact.

Three categories of elements, based on the main domains of spatial interventions, unfold from each sphere: free-standing, building-related, and quasi-public and "squat" for private installations; streetscape, permeable pavers and depaving, and green-blue infrastructure for civic installations.

The categories of climate-responsive design elements ( $\tan$ boxes) are allocated throughout the different categories of CG elements. This distribution relates to the domains of spatial interventions to which both categories concur; where an overlap can be found between CG and climate-responsive elements. For each category, Figure 7 presents the climate-responsive urban design goals behind the employment of these elements (yellow boxes). The categories of climate-responsive elements and goals can be found in more than one domain of CG spatial interventions, whenever the CG elements listed fall within their scope.

Evidently, the way the climate-responsive design goals can be achieved through the CG elements identified is not straightforward, nor should it be regarded as the holy grail of the adaptation of outdoor urban environments to urban heat. For example, a trellised tree is a common building-related CG element. However, its capacity to help in controlling solar radiation depends on aspects such as the size and shape of the tree crown (amount of shade), its leaf density (potential for evaporative cooling), or its placement with respect to other structures or elements (shading pattern).

\subsection{A Meta-Level Reciprocity}

Beyond the core reciprocity presented in Figure 7, we were able to identify a meta-level reciprocity between CG and climate-responsive urban design. Three aspects are called forth here: CG occur mainly where climate-responsive design is most needed; CG comprise (necessarily) site-specific interventions; and CG foster thermal adaptation.

\subsubsection{Convivial Greenstreets Occur Mainly where Climate-Responsive Design is Most Needed}

The adaptation of urban areas to climate change is most challenging in compact areas, where changes to the urban form (e.g., street orientation, built density, average heights, built heritage, infrastructure) are difficult, at least compared to newly built areas [3]. While it is known that the urban form directly impacts urban microclimates [48], it is not likely that an entire block or a building listed as heritage will be demolished to improve, say, wind flow in an outdoor space. It follows that newly built forms are just the tip of the iceberg and that a more sustainable built environment calls for action upon existing buildings and infrastructures (and spaces) [49]. Lenzholzer [25] proposed the concept of the climatope, i.e., an urban area or district with typical microclimatic characteristics based on the predominant land use and building density. The areas where CG typically occur correspond to high-density climatopes, namely the "city", "city center", and "commercial district". These climatopes commonly correspond to the most critical areas regarding phenomena like the urban heat island. 
This means that CG occur in areas where climate-responsive design solutions are most needed. Because CG mostly occur in these dense, yardless urban cores, they hold the potential to contribute to tackling urban climate problems actively.

\subsubsection{Convivial Greenstreets Comprise (necessarily) Site-Specific Interventions}

Typical CG interventions are not replicable because they do not follow any pattern nor possess any meta-goal beyond the simple and quite straightforward wish to increase the enjoyment of the streetscape. The decision to intervene may be influenced, say, by a neighbor. A neighbor's intervention might be influential/inspirational. However, this influence does not prescribe a spatial configuration. Interventions are tailormade as people who conceive of CG live or work there and build and nurture them with their own hands. We argue that this can serve the need for climate-responsive urban design to originate site-specific solutions. Because CG result from spontaneous private initiatives adjusting the streetscape to particular wishes, climate-wise, they can efficiently contribute to meeting the thermal comfort needs of individuals or small groups. For instance, a resident knows exactly where a tree needs to be planted so as to cast a shadow where it is most needed. Citizens might not be (at least not a majority) aware that they can contribute to the climate adaptation of their street. Nevertheless, even if unconsciously, the combination of physical microclimatic variables and long-term thermal experiences is likely to lead them to make interventions delivering local effects tailored to their needs and preferences.

\subsubsection{Convivial Greenstreets Foster Thermal Adaptation}

Most elements commonly employed in CG are small (e.g., sunshades or flowerpots). This makes it easy for people to adjust these elements in response to changing daytime or seasonal conditions, or to entirely change/replace a CG element in case it does not perform well. A sunshade can be easily opened or closed. A potted plant can be easily moved to a different place. If a plant dies, residents can promptly replace it by another. These are examples of aspects fostering thermal adaptation in CG and, thus, people's capacity to adjust to changing microclimatic conditions and varying thermal comfort needs.

\section{Discussion}

We argue that there is a reciprocity between CG and climate-responsive design that holds the potential for CG to become an emerging green practice addressing urban heat problems while supporting social engagement outdoors. However, CG are eminently spontaneous phenomena. As such, they should not be co-opted as an academic or aesthetic prescriptive tool. The conceptual framework presented in this paper is focused on informal private sector initiatives and celebrates the social side of the equation.

This framework can be traced back to Ivan Illich's seminal book Tools for Conviviality [50]. In this critique of industrial society, Illich criticized the rise of professionalism and made an appeal to "enlarge the range of each person's competence, control, and initiative, limited only by other individuals' claims to an equal range of power and freedom" [50] (p. 12). This idea also echoes Christopher Alexander's "timeless way of building", a process according to which "the order of a building or a town grows out directly from the inner nature of the people, and the animals, and plants, and matter which are in it" [51] (p. 7). Tamminga [2] (p. 1129) added that place-based conviviality in cities "connotes a kind of inclusive multi-community neighbourliness that embraces difference and exchange." Other authors concurred about this view by stating conviviality in cities as the very essence of civil society and urbanity [52,53].

For climate adaptation, the private initiative of local inhabitants is as relevant as public (i.e., top-down) interventions in the public streetscape. Beery [54] (p. 14) argued that "community-based climate change adaptation is unique" and that uniqueness calls for mobilizing community stakeholders to explore climate adaptation from their unique perspective. In the case of CG, residents, shopkeepers, 
and employees can play a relevant role in greening the street adjacent to their houses, shops, or offices. For example, private components of the streetscape determine the amount of greenery adjacent or on facades or the permeable/impermeable ratio of front and back yards (where they exist). Often involving consent from municipalities, private initiative can also be taken over public components of the streetscape (e.g., depaving parts of street pavements or increasing planting in street tree root zones).

Public and private interventions are the two dimensions of cityscapes. Eventually, climate-resilience can be more effectively addressed if the city is regarded as one cohesive body of intervention, and if public and private initiatives, bottom-up and top-down instruments are combined smartly. In the context of urban socio-ecological systems, integrating these domains entails an engaged private sector characterized by knowledge creation, authorship, and initiative.

\subsection{The Issue of Academization}

Articulating the informal private sector initiative aspects with the potential for CG to become operational in climate-responsive design is challenging. On the one hand, the spontaneous character of CG should be secured. On the other hand, the challenges currently posed to cities, amongst which urban heat is only but one, call for design research products discussable on objective parameters [55]. In particular, evidence-based applicable design knowledge comprising a certain level of replicability $[56,57]$ can assist design practitioners with addressing new design challenges. Here, by determining upfront a set of performance criteria that ought to be met by a design, one can judge the success(es) or failure(s) of different design ideas [58,59].

Research and theory are of utmost importance in urban design, and we do not imply that they should be disregarded. Our point is that, within the scope of this article, there is a thin border between developing applicable design knowledge that is suggestive or prescriptive to citizens. The latter should be avoided in order to not compromise the creativity and spontaneity intrinsic to CG. The informal and societal entourage of CG, perhaps even more than in urban design practice, has implicitly full creative freedom. In CG, creative freedom is arguably only limited by one's will and means available, and by the spatial characteristics of the streetscape and its adjacent land uses. However, to become operational in climate-responsive urban design, there is a need to understand and communicate CG with some degree of objectiveness and replicability. We argue that this should be made in a suggestive way, i.e., in the sense of assisting inhabitants, designers, and decision-makers with expanding the installation of CG, in an inspirational instead of determinant way (see more in Section 4.3).

\subsection{The Issue of Aesthetics}

Conceptualizing the potential of CG to become an emerging green practice for urban adaptation to climate change raises questions around aesthetic properties commonly comprised in urban design and landscape architecture. We refer to properties that afford aesthetic experience for the many through beauty and/or meaning [60,61]. Based on the conceptualization of CG made to date, and on the ethnographic approaches informing it, we argue that even though CG may eventually induce aesthetic responses, this does not necessarily result from a conscious use (as in the deliberate incorporation of properties to achieve an expected effect) of aesthetic properties, at least not to the same extent as in the disciplines of urban design or landscape architecture. This needs to be further explored and assessed by future research.

Convivial greenstreets comprise aesthetic properties (e.g., beauty, ugliness, elegance, balance) circumscribed to the imaginative tastes and impulses of individuals or a small group of individuals, within the means they have available. The streetscape is composed of several assemblages of elements that create idiosyncratic "urban frames" within the limits of a private component of the streetscape (e.g., the width of a residential facade; "overlap" installations that squat on the public domain).

The CG elements presented in Figure 7 are combined in endless ways, and we expect more items may be added as novel forms appear. Each of these ways is highly specific and subjective. The resulting urban frame and the process of creating it are not meant to be reproduced, to inform the development 
of new CG practices, nor to potentiate disciplinary advances around aesthetics. CG do not follow any firm pattern. Certainly, an urban frame can be appreciated as beautiful, ugly, sophisticated, kitschy, tacky, humorous, sublime, or uncanny. However, whatever their aesthetic appeal, as in the aesthetic response triggered in people by a landscape [62], this appeal is not likely to result from an in-depth dive into philosophical considerations around the aesthetics of a landscape, but more from spontaneous ad hoc manifestations of personal intentions materialized by the means at hand. CG are probably the most straightforward manifestation of the idea that what makes spaces public is not their ownership status, physical design, or aesthetic appearance, but rather the experiences people are able to create and share within it [63].

We do not imply that aesthetic appeal is unimportant. Likewise, we do not claim that being academic compromises imagination in urban design or landscape architecture. Our argument is that, as informal private sector phenomena, CG do not necessarily comply, do not need to comply, and should not comply with aesthetic considerations commonly embedded in products from design disciplines. CG cannot be interpreted nor appreciated as an object of formal design.

Our site observations suggested that CG practitioners embrace a wide range of motivations. Certainly, they possess what most professionals struggle to achieve: situated knowledge. Thus, when conceptualizing the operationalization of CG in climate-responsive design, it is important to ensure that their aesthetic appeal does not result from an instrumentalization that alienates CG from their spontaneous, informal, ad hoc character. Becoming aware of the vital force of informal design and horticultural bricolage in the city should give professional pause because "disciplinary parochialism" [64] can so easily counteract local creativity. We concur, then, with Simon [65] (p. 55), who asserted that "everyone designs who devises courses of action aimed at changing existing situations to preferred ones". In this light, we begin to understand the CG we have been observing as "design microdemocracies".

Finally, seemingly presaging the vital reciprocity between CG and climate-responsive design, Krippendorff [66] (pp. 7-8) wrote:

"If designers realize that they cannot force their conceptions onto others, and that whatever they propose must resonate with stakeholder conceptions, the questions that designers need to ask are implicitly ethical. The only ethical principle I would add is to avoid monopolizing design in a profession and instead delegate the practice to as many stakeholders as possible. Design is a basic human activity to which everyone should have access."

\subsection{How to Avoid the Academization and Aestheticizing of the Convivial Greenstreets' Concept While Making It Operational in Climate-Responsive Urban Design?}

When we conceive of the relevance of CG for climate-responsive urban design, it is not in the sense of its instrumentalization, but more in the sense of understanding and accepting it within a climate-responsive design schema as an informal private sector phenomenon. Our stance is that the operationalization of CG in climate-responsive design should be about finding a compromise between securing the informal character of CG and dissecting objective parameters upon which to base discussions on the ways CG can address urban microclimates.

When tackling urban heat, design solutions should be local enough to induce effective cooling effects. This fits well the informal subjective character of CG and its multiple aesthetic manifestations. Thus, the initiative of citizens in adapting cities to urban heat needs to be cherished and encouraged, and its relevance clearly communicated to them in a way that enables their full creative freedom. Securing the informal character of CG while making them operational during climate-responsive urban design can then be best achieved by communicating the reciprocity between CG elements and climate-responsive elements and goals in a suggestive manner.

On this perspective, we argue that making CG operational in climate-responsive urban design while avoiding its academization and aestheticizing can be achieved by: 
1. Informing inhabitants on how their informal, spontaneous, and ad hoc interventions on the streetscape can boost conviviality and the climate-responsiveness of cities. Private initiative can play a vital role in the climate adaptation of our living environments. However, people are mostly unaware of this, and conventional top-down approaches to city-making often prevent it.

2. Informing urban designers and other early-adopters on how to incorporate CG into a design schema without, however, imposing any deterministic procedure or design solution on local populations. Designers can find ways of integrating CG into their design schemas while ensuring internal and external coherence. We hold the view that designers may eventually provide hints to inhabitants on the previous bullet point, for example during participatory processes around the development of a design schema, but giving them full latitude to create their own non-academized nor professionalized "urban frames".

In order to ensure that the measures implemented within CG actually deliver climate-adaptive effects, communication and discussion with citizens and designers/early-adopters should be based on objective parameters around the reciprocity between CG and climate-responsive urban design. As a way of exploring how this can be achieved, we developed a group of visualizations (Figures 8-13). With the two bullet points above and these visualizations, we made progress on answering the question addressed in this paper.
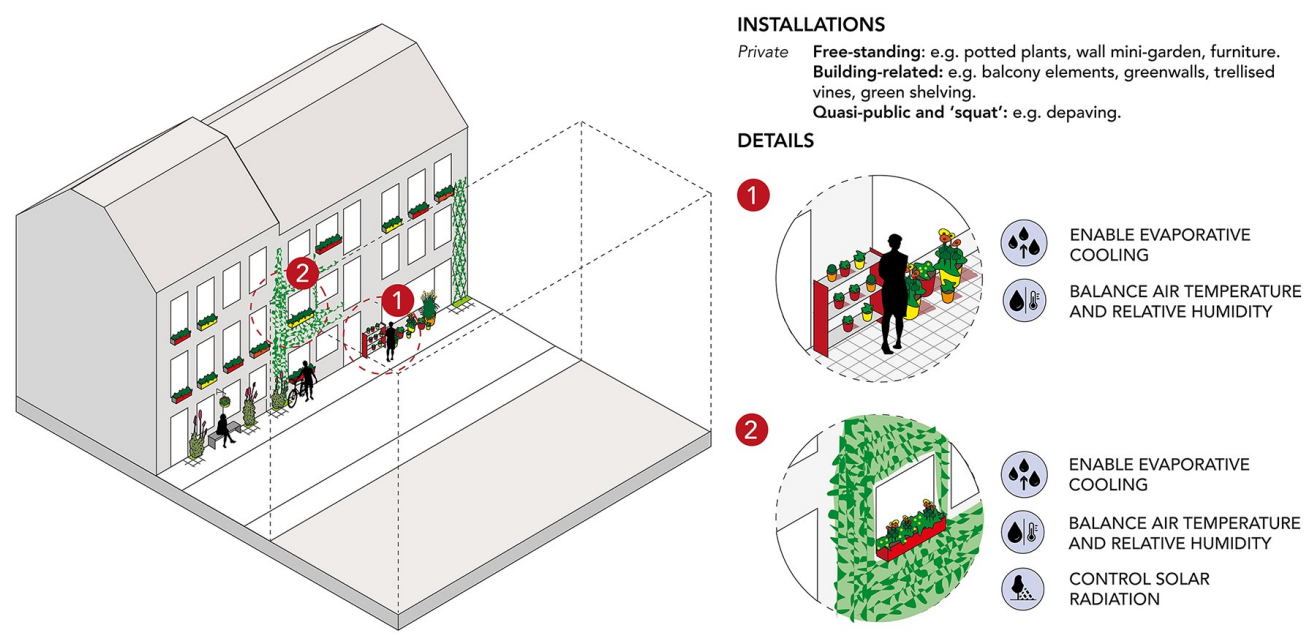

Figure 8. Visualization of the combination of convivial greenstreets' elements with climate-responsive urban design goals for Sub-type 1a. residential.
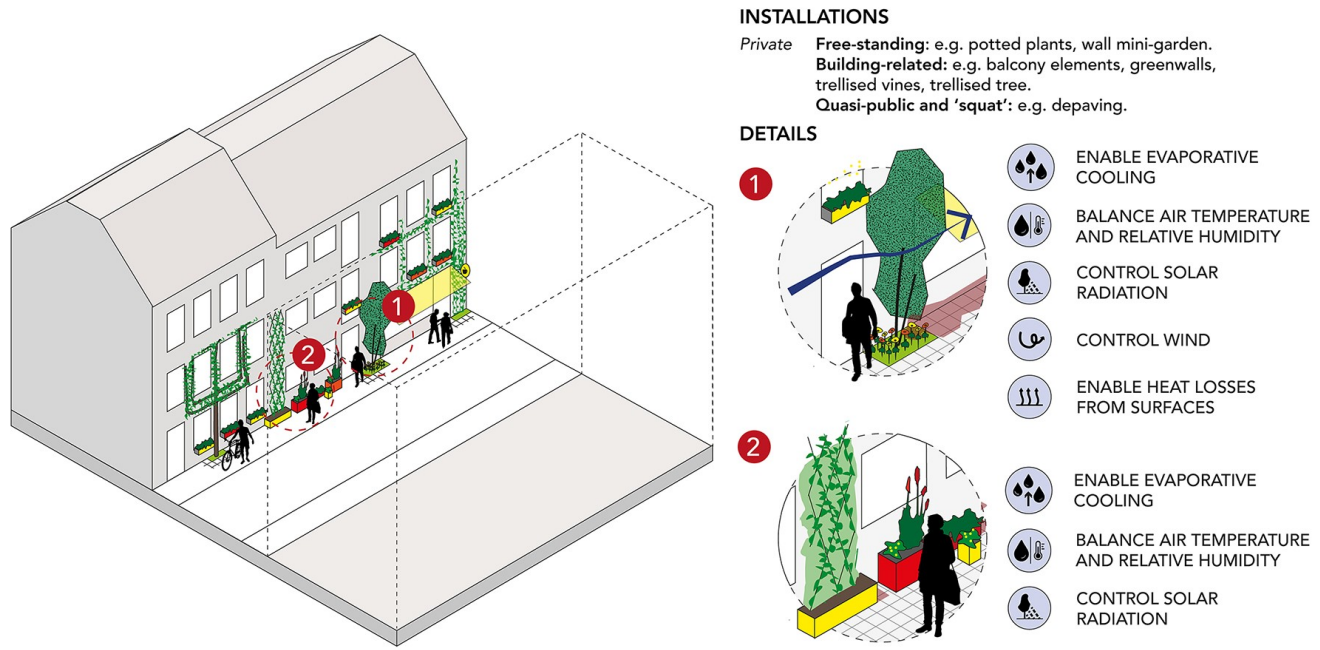

Figure 9. Visualization of the combination of convivial greenstreets' elements with climate-responsive urban design goals for Sub-type 1b. mainly residential. 


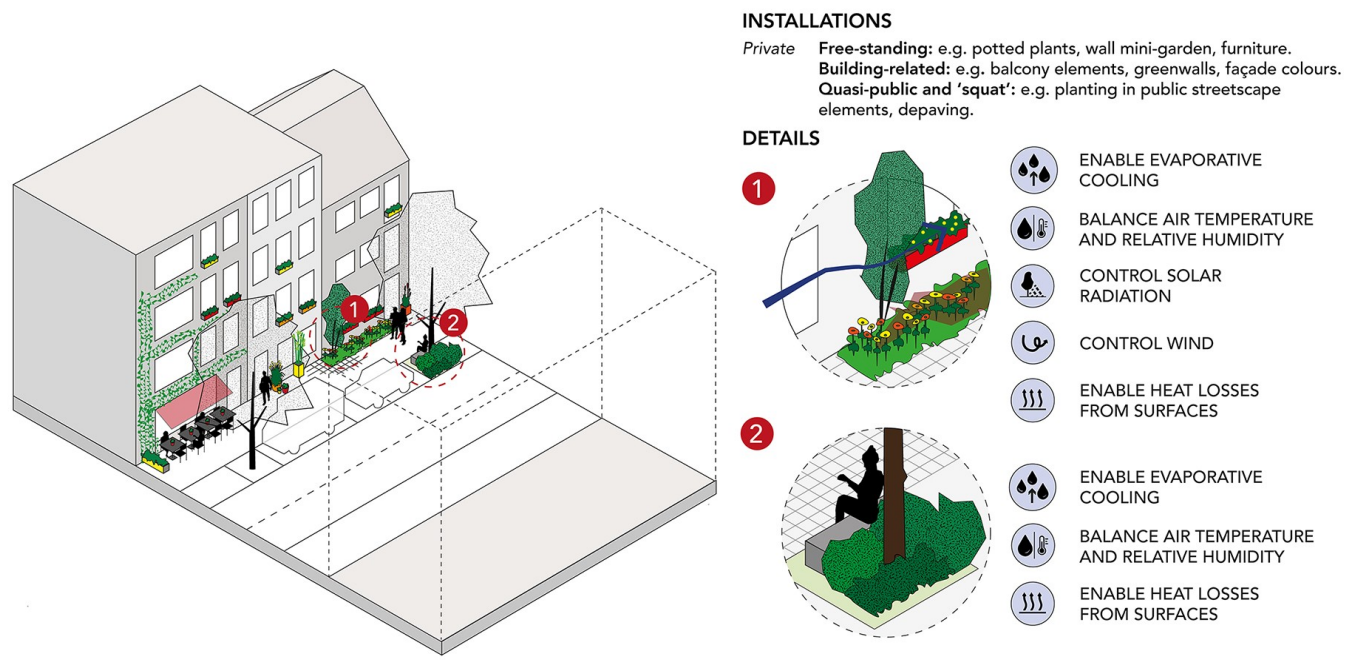

Figure 10. Visualization of the combination of convivial greenstreets' elements with climate-responsive urban design goals for Sub-type 2a. mixed commercial/small scale.
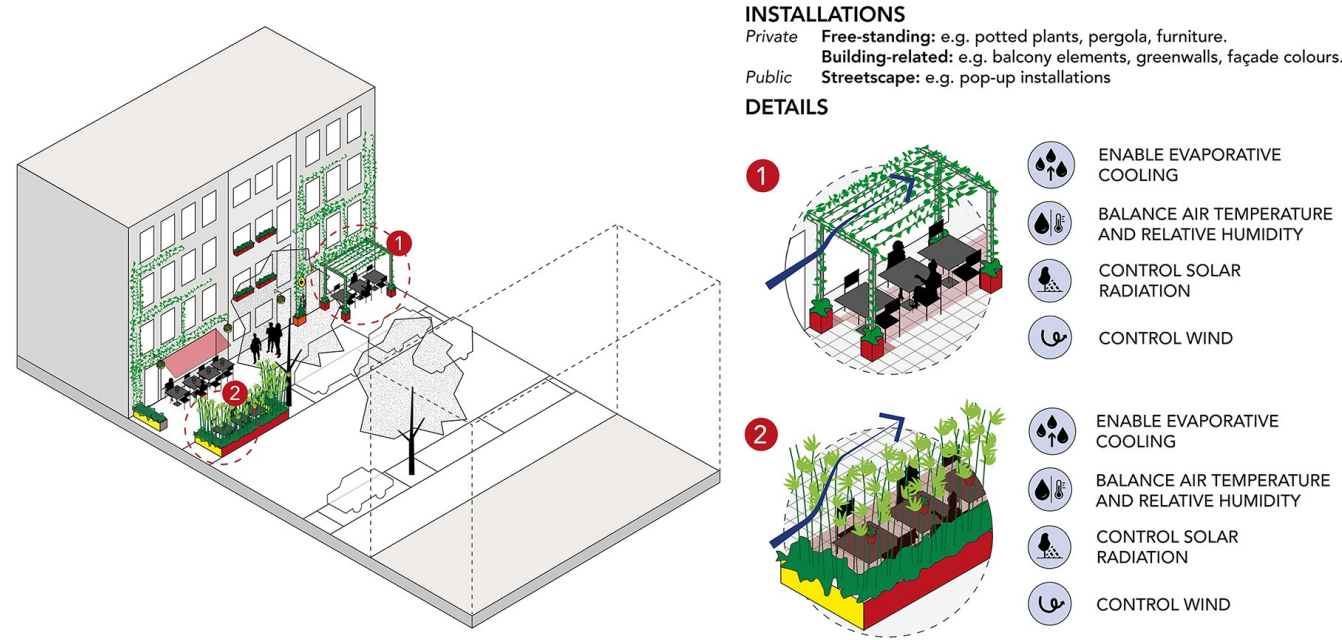

Figure 11. Visualization of the combination of convivial greenstreets' elements with climate-responsive urban design goals for Sub-type $2 \mathrm{~b}$. mixed commercial/large scale.

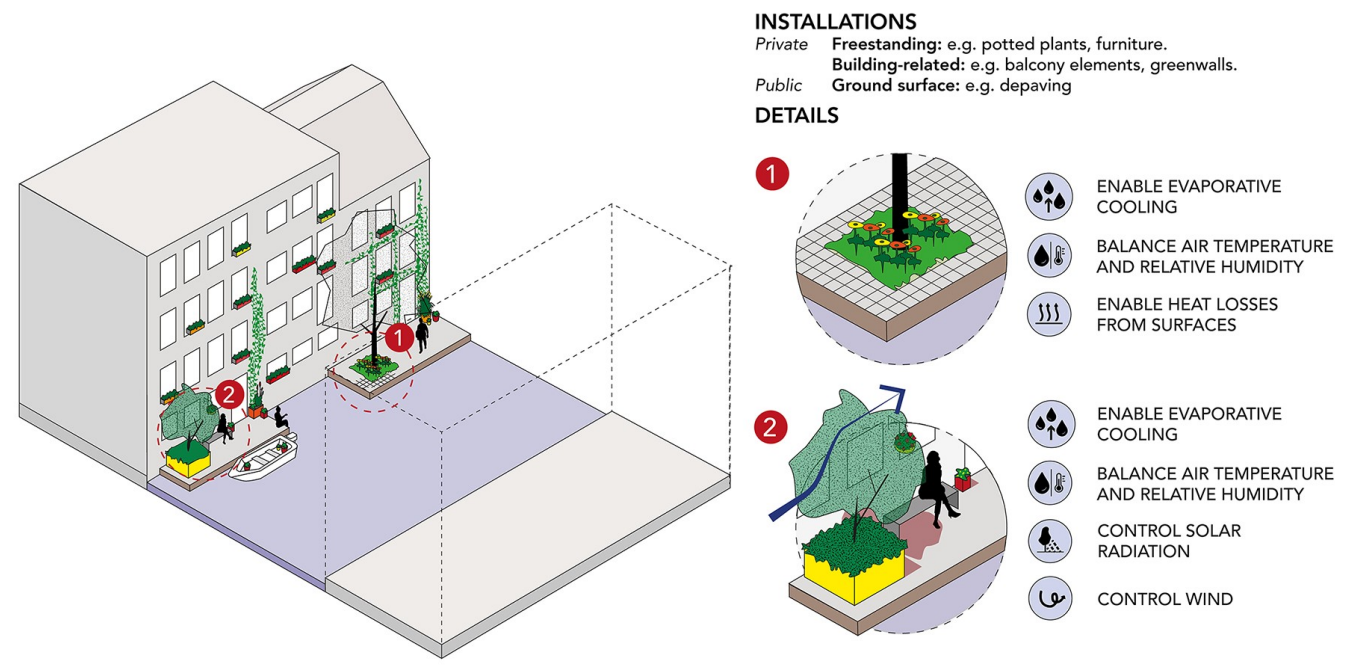

Figure 12. Visualization of the combination of convivial greenstreets' elements with climate-responsive urban design goals for Type 3. waterway. 

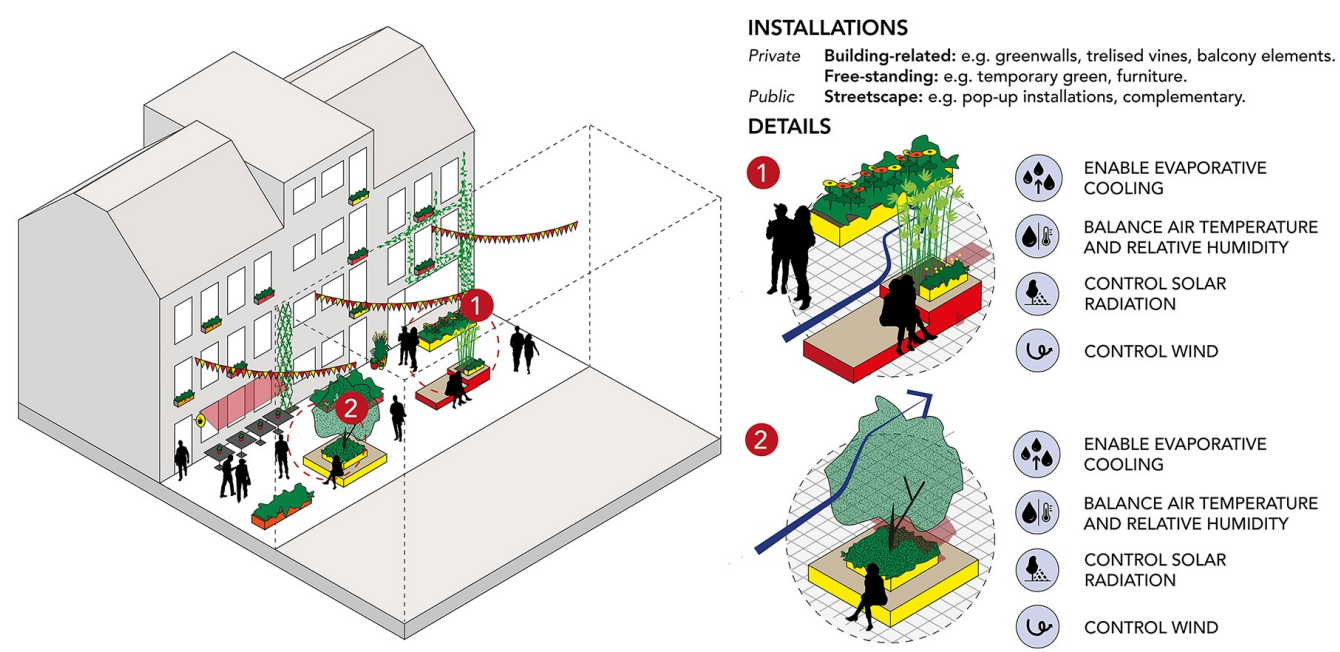

Figure 13. Visualization of the combination of convivial greenstreets' elements with climate-responsive urban design goals for Type 4 . celebratory and artistic.

These visualizations offer the "anatomy" underlying the reciprocity between the intrinsic vitality and inclusiveness of CG and climate-responsive design. The visualizations are axonometric drawings depicting each CG type, based on Table 2, and intersecting typical CG elements with the overarching goals of climate-responsive design, based on Figure 7. Each visualization is populated with cut-outs of people (adapted from https://skalgubbar.se) indicating the ambience of each CG type. Zoom-ins are provided per visualization. Each zoom-in presents a group of CG elements depicted and the applicable, likely climate-responsive goals. The goals are communicated textually and through icons in order to communicate invisible microclimatic effects as clearly as possible.

The allocation of CG elements per type was based on the opportunities for implementing elements offered by the street profile and by the predominant adjacent land uses (see Table 2). The street profile determines the space available for free-standing, building-related, or quasi-public and "squat" interventions (see Table 2 and Figure 7). Narrower streets (frequently occurring in Types 1a, 1b, and 3) are often more restricted to building-related elements, such as greenwalls, balcony elements, or small potted plants. In turn, wider streets (frequently occurring in Types $2 a$ and $2 b$ ), in addition to building-related elements, allow more and larger free-standing elements, such as potted plants and wall min-gardens, as well as quasi-public and "squat" elements, such as planting in public streetscape elements or depaving. All types comprise both wider and narrower street profiles. The elements depicted in the visualizations took into account frequently occurring street profiles for each type, so that both wide and narrow situations could be exemplified. However, there was an immense variation in street profiles. Thus, for example, Type $2 a$, herewith taken frequently as a wide street, was not necessarily always wider than Type $1 \mathrm{~b}$, taken frequently as a narrow street.

Relative to adjacent land uses, the representation of residential, commercial, and institutional functions influences the type of initiatives and, thus, elements. When residential and small commercial uses are predominant, so is the likelihood for private installations such as (building-related) potted plants or green shelving, or small informal café terraces (free-standing). When larger scale commercial and, especially, institutional uses are the majority, public installations such as pop-up gardens or ancillary decorative elements (streetscape) are more likely to occur.

The allocation of CG elements in these visualizations is a streamlined exemplification of countless spatial configurations possible in practice. As abstracted environments, i.e., not representing any specific site, the visualizations did not include the myriad of spatial configurations that could be found in real life. Likewise, the CG elements depicted did not cater to all possible CG elements. The aim was to offer a visual synthesis of elements by reference to the two main groups of installations (private and public) behind CG. 
By synthesizing graphically the information presented in Table 2 and Figure 7, these visualizations are likely to reach different stakeholders. This is based on previous research around the potential of using landscape visualizations for communicating adaption to climate change and climate-responsive design [67-69]. Based on these studies, communicating visually the reciprocity between CG and climate-responsive design herewith explored may foster cooperation during the implementation of CG throughout urban areas. This reciprocates the idea that "Basic engineering knowledge will empower communities to take ownership of resilience actions, while working with relevant authorities" [70] (p. 11). Doing it visually can better reach, and therefore mobilize, a variety of stakeholders. The visualizations can work as inspiration sources for citizens, as design tools assisting designers with integrating the CG concept into a design schema, or as resources assisting educators with raising awareness and triggering younger generations to act on street-based conviviality and climate-responsiveness.

\subsection{Limitations and Further Research}

The study presented herein was a preliminary approach to the topic. As such, it provided a foundation for future research. Our conceptual framework suggested an agenda strongly rooted on previous research. However, this agenda needs to confirm, expand, and quantify the potentialities of interweaving CG and climate-responsive design and, thus, of operationalizing the former within the latter while keeping its spontaneous character.

This paper opens the way toward unleashing the potential that a network of cool CG has to promote the climate adaptation of cities, or parts of cities, around the globe. One intervention alone is not likely to result in noticeable cooling effects within the urban canyon. However, the juxtaposition of interventions at the city precinct or metropolis scale may. These are some of the aspects that need to be investigated with field measurements and/or micrometeorological simulations. Future research should also include active means of engaging local actors into expanding, for instance, on the issue of aesthetics, and scholars on the issue of academization.

\section{Conclusions}

With this introductory explorative study, we argued that convivial greenstreets can be used as an active resource for urban adaptation to climate change, while preventing its academization and aestheticizing, in two ways: by informing citizens that convivial greenstreets can boost conviviality and the climate-responsiveness of cities, so that these become a more systematic city-making practice; and by stimulating urban designers and other early-adopters to incorporate convivial greenstreets into a design schema, and to suggest to local populations how to undertake their own installations while ensuring that these informal interventions fit into a coherent climate-responsive design proposal.

In this preliminary exploration, we observed that the reciprocity between convivial greenstreets and climate-responsive urban design happens at two levels. At the core level, convivial greenstreets were applied over the whole streetscape. Thus, they dealt with holistic solutions encompassing ground surfaces and buildings' facades, which are key to influence urban microclimates significantly. Next, convivial greenstreets comprise spatial (mostly green) elements frequently used in climate-responsive urban design. At the meta-level, convivial greenstreets occur mainly where climate-responsive design is most needed, i.e., dense yardless urban cores; comprise site-specific interventions that can serve the need for climate-responsive urban design to originate site-specific solutions; and foster thermal adaptation, as most of its elements are small and, thus, easily adjustable. It is the combination of these two levels of reciprocity that sustains the potential in using convivial greenstreets as a concept for climate-responsive urban design and, thus, to help with prompting action on urban resilience.

These conclusions set the agenda for future research. We believe that the co-operation between convivial greenstreets and climate-responsive urban design is key to promote resilient interventions throughout dense city landscapes, and we anticipate that convivial greenstreets will continue emerging as a green practice with positive impacts on urban adaptation to climate change. 
Author Contributions: Conceptualization, K.T. and J.C.; funding acquisition, K.T.; investigation, K.T. and J.C.; methodology, K.T. and J.C.; supervision, J.C.; visualization, M.B.; writing-original draft, K.T. and J.C.; writing-review and editing, K.T., J.C., and M.B. Unless otherwise noted, all photographs were by the authors. All authors have read and agreed to the published version of the manuscript.

Funding: This research was partially funded by Penn State University's College of Arts and Architecture.

Conflicts of Interest: The authors declare no conflict of interest.

\section{References}

1. Tamminga, K. Convivial Greenstreets as Force and Context for Urban Sustainability. In Proceedings of the 4th World Sustainability Forum, Basel, Switzerland, 1-30 November 2014.

2. Tamminga, K. Green infrastructure in liminal streetside spaces: Cases from European city cores. In Proceedings of the AESOP Annual Congress '17: Spaces of Dialog for places of Dignity: Fostering the European Dimension of Planning, Lisbon, Portugal, 11-14 July 2017.

3. Cortesão, J. Thermal Retrofitting of Public Spaces in Compact Urban Areas. A Bioclimatic Approach. Ph.D. Thesis, Porto University, Porto, Portugal, 2013.

4. Kusenbach, M. Street phenomenology: The go-along as ethnographic research tool. Ethnography 2003, 4, 455-485. [CrossRef]

5. Tilley, C. Interpreting Landscapes: Explorations in Landscape Phenomenology; Left Coast Press: Walnut Creek, CA, USA, 2010.

6. Nuvolati, G. The Flâneur: A way of walking, exploring and interpreting the city. In Walking in the European City: Quotidian Mobility and Urban Ethnography; Shortell, T., Brown, E., Eds.; Ashgate Publishing: Surrey, UK, 2014; pp. 21-40.

7. Ramsden, H. A walk around the block: Creating spaces for everyday encounters. In Walking in the European City: Quotidian Mobility and Urban Ethnography; Shortell, T., Brown, E., Eds.; Routledge: London, UK, 2014; pp. 225-244.

8. Wenger, E. Communities of Practice: Learning, Meaning and Identity; Cambridge University Press: New York, NY, USA, 1998.

9. Nikolopoulou, M. (Ed.) Designing Open Spaces in the Urban Environment: A Bioclimatic Approach. RUROS: Rediscovering the Urban Realm and Open Spaces; Centre for Renewable Energy Sources: Pikermi Attiki, Greece, 2004.

10. Klok, L.; Kluck, J. Reasons to adapt to urban heat (in The Netherlands). Urban Clim. 2018, 23, 342-351. [CrossRef]

11. Grimmond, C.; Roth, M.; Oke, T.R.; Au, Y.C.; Best, M.; Betts, R.; Carmichael, G.; Cleugh, H.; Dabberdt, W.; Emmanuel, R.; et al. Climate and more sustainable cities: Climate information for improved planning and management of cities (Producers/Capabilities Perspective). Procedia Environ. Sci. 2010, 1, 247-274. [CrossRef]

12. Gaitani, N.; Mihalakakou, G.; Santamouris, M. On the use of bioclimatic architecture principles in order to improve thermal comfort conditions in outdoor spaces. Build. Environ. 2007, 42, 317-324. [CrossRef]

13. Nikolopoulou, M.; Baker, N.; Steemers, K. Thermal comfort in outdoor urban spaces: Understanding the Human parameter. Sol. Energy 2001, 70, 227-235. [CrossRef]

14. Thorsson, S.; Lindqvist, M.; Lindqvist, S. Thermal bioclimatic conditions and patterns of behaviour in an urban park in Goteborg, Sweden. Int. J. Biometeorolgy 2004, 48, 149-156. [CrossRef]

15. Shishegar, N. Street Design and Urban Microclimate: Analyzing the Effects of Street Geometry and Orientation on Airflowand Solar Access in Urban Canyons. J. Clean Energy Technol. 2013, 1, 52-56. [CrossRef]

16. Cuadrat, J.M.; Pita, M.F. Climatología; Ediciones Cátedra: Madrid, Spain, 2009.

17. Schmid, A.L. A Idéia de Conforto. Reflexões Sobre o Ambiente Construído; Pacto Ambiental: Curitiba, Brazil, 2005.

18. Klemm, W.; Heusinkveld, B.; Lenzholzer, S.; van Hove, B. Street greenery and its physical and psychological impact on thermal comfort. Landsc. Urban Plan. 2015, 138, 87-98. [CrossRef]

19. Reis, C.; Lopes, A. Evaluating the cooling potential of urban green spaces to tackle urban climate change in Lisbon. Sustainability 2019, 11, 2480. [CrossRef]

20. Meerow, A.; Black, R. Landscaping to Conserve Energy: A Guide to Microclimate Modification. Energy Information Document 1028; University of Florida: Gainesville, FL, USA, 1991. 
21. Shashua-Bar, L.; Hoffman, M. Vegetation as a climatic component in the design of an urban street: An empirical model for predicting the cooling effect of urban green areas with trees. Energy Build. 2000, 31, 221-235. [CrossRef]

22. Papadakis, G.; Tsamis, P.; Kyritsis, S. An experimental investigation of the effect of shading with plants for solar control of buildings. Energy Build. 2001, 33, 831-836. [CrossRef]

23. Higueras, E. Urbanismo Bioclimático; Editorial Gustavo Gili: Barcelona, Spain, 2006.

24. Nikolopoulou, M.; Steemers, K. Thermal comfort and psychological adaptation as a guide for designing urban spaces. Energy Build. 2003, 35, 95-101. [CrossRef]

25. Lenzholzer, S. Weather in the City; nai010 publishers: Rotterdam, The Netherlands, 2015.

26. Taylor, B.; Guthrie, P. The first line of defence: Passive design at an urban scale. In Proceedings of the Air Conditioning and the Low Carbon Cooling Challenge Conference, London, UK, 27-29 July 2008.

27. Matsuoka, R.; Kaplan, R. People needs in the urban landscape: Analysis of Landscape And Urban Planning contributions. Landsc. Urban Plan. 2008, 84, 7-19. [CrossRef]

28. Andersson, E.; Barthel, S.; Borgström, S.; Colding, J.; Elmqvist, T.; Folke, C.; Gren, Å. Reconnecting cities to the biosphere: Stewardship of green infrastructure and urban ecosystem services. Ambio 2014, 43, 445-453. [CrossRef] [PubMed]

29. Niemelä, J.; Saarela, S.R.; Söderman, T.; Kopperoinen, L.; Yli-Pelkonen, V.; Väre, S.; Kotze, D.J. Using the ecosystem services approach for better planning and conservation of urban green spaces: A Finland case study. Biodivers. Conserv. 2010, 19, 3225-3243. [CrossRef]

30. de Morais, M.V.B.; Guerrero, V.V.U.; de Freitas, E.D.; Marciotto, E.R.; Valdés, H.; Correa, C.; Agredano, R.; Vera-Puerto, I. Sensitivity of radiative and thermal properties of building material in the Urban atmosphere. Sustainability 2019, 11, 6865. [CrossRef]

31. Fanger, P.O. Thermal Comfort: Analysis and Applications in Environmental Engineering; McGraw-Hill: New York, NY, USA, 1972.

32. Bretz, S.; Akbari, H.; Rosenfeld, A. Practical Issues for Using Solar-Reflective Materials to Mitigate Urban Heat Islands. Atmos. Environ. 1998, 32, 95-101. [CrossRef]

33. Santamouris, M.; Synnefa, A.; Karlessi, T. Using advanced cool materials in the urban built environmen to mitigate heat islands and improve thermal comfort conditions. Sol. Energy 2011, 85, 3085-3102. [CrossRef]

34. Pomerantz, M.; Akbari, H.; Chen, A.; Taha, H.; Rosenfeld, A.H. Paving Materials for Heat Island Mitigation; Ernest Orlando Lawrence Berkeley National Laboratory: Berkeley, CA, USA, 1997.

35. Brown, R. Design with Microclimate: The Secret to Comfortable Outdoor Spaces; Island Press: Washington, DC, USA, 2010.

36. Nakayama, T.; Fujita, T. Cooling effect of water-holding pavements made of new materials on water and heat budgets in urban areas. Landsc. Urban Plan. 2010, 96, 57-67. [CrossRef]

37. Kleerekoper, L. Urban Climate Design. Improving Thermal Comfort in Dutch Neighbourhoods. Ph.D. Thesis, Delft University of Technology, Delft, The Netherlands, 2016.

38. Echols, S.; Pennypacker, E. Artful Rainwater Design: Creative Ways to Manage Stormwater; Island Press: Washington, DC, USA, 2015.

39. Backhaus, A.; Dam, T.; Jensen, M.B. Stormwater management challenges as revealed through a design experiment with professional landscape architects. Urban Water J. 2012, 9, 29-43. [CrossRef]

40. Van Hove, L.W.A.; Jacobs, C.M.J.; Heusinkveld, B.G.; Elbers, J.A.; van Driel, B.L.; Holtslag, A.A.M. Temporal and spatial variability of urban heat island and thermal comfort within the Rotterdam agglomeration. Build. Environ. 2015, 83, 91-103. [CrossRef]

41. Jacobs, C.; Klok, L.; Bruse, M.; Cortesão, J.; Lenzholzer, S.; Kluck, J. Are urban water bodies really cooling? Urban Clim. 2020, 32, 100607. [CrossRef]

42. Solcerová, A. Water as a Coolant of Cities. Ph.D. Thesis, Delft University of Technology, Delft, The Netherlands, 2018.

43. Cortesão, J.G.; Alves, F.B.; Corvacho, H.; Rhodes, M. The climatic skin of urban spaces. Int. J. Hous. Sci. Appl. 2009, 33, 105-115.

44. Akbari, H.; Damon Matthews, H.; Seto, D. The long-term effect of increasing the albedo of urban areas. Environ. Res. Lett. 2012, 7, 024004. [CrossRef]

45. Akbari, H.; Rose, L.S. Urban Surfaces and Heat Island Mitigation Potentials. J. Hum. Environ. Syst. 2008, 11, 85-101. [CrossRef] 
46. Oke, T.R. Street design and urban canopy layer climate. Energy Build. 1988, 11, 103-113. [CrossRef]

47. Morakinyo, T.E.; Kong, L.; Lau, K.K.-L.; Yuan, C.; Ng, E. A study on the impact of shadow-cast and tree species on in-canyon and neighborhood"s thermal comfort. Build. Environ. 2017, 115, 1-17. [CrossRef]

48. Yang, J.; Shi, B.; Xia, G.; Xue, Q.; Cao, S.J. Impacts of Urban form on Thermal Environment near the Surface Region at Pedestrian Height: A Case Study Based on High-density Built-up Areas of Nanjing City in China. Sustainability 2020, 12, 1737. [CrossRef]

49. Jones, P. Practical evaluation tools for urban sustainability. Indoor Built Environ. 2007, 16, 201-203. [CrossRef]

50. Illich, I. Tools for Conviviality; Harper \& Row: New York, NY, USA, 1973.

51. Alexander, C. The Timeless Way of Building; Oxford University Press: New York, NY, USA, 1979.

52. Peattie, L. Convivial cities. In Cities and Citizens: Planning and the Rise of Civil Society in a Global Age; Douglass, J., Friedmann, J., Eds.; John Wiley \& Sons: Chichester, UK, 1998; pp. 247-252.

53. Nowicka, M.; Vertovec, S. Comparing convivialities. Eur. J. Cult. Stud. 2014, 17, 341-356. [CrossRef]

54. Beery, T. Exploring the role of outdoor recreation to contribute to urban climate resilience. Sustainability 2019, 11, 6268. [CrossRef]

55. Cortesão, J.; Lenzholzer, S.; Klok, L.; Jacobs, C.; Kluck, J. Generating applicable urban design knowledge. J. Urban Des. 2019, 25, 293-307. [CrossRef]

56. Lenzholzer, S.; Nijhuis, S.; Cortesão, J. RTD in landscape architecture: A first State of the Art. In Proceedings of the Design Research Society 2018 Conference, Limmerick, Ireland, 25-28 June 2018; pp. 382-394.

57. Dorst, K. Design beyond Design. She Ji 2019, 5, 117-127. [CrossRef]

58. Barnett, R. Exploration and discovery: A nonlinear approach to research by design. Landsc. Res. 2000, 6, $25-40$.

59. Breen, J. Designerly enquiry. In Ways to Study and Research Urban, Architectural and Technical Design; van der, V.D., de Jong, T.M., Eds.; Delft University Press: Delft, The Netherlands, 2002; pp. 95-102.

60. Carroll, N. Philosophy of Art: A Contemporary Introduction; Routledge: London, UK, 1999.

61. Beardsley, M. Aesthetics: Problems in the Philosophy of Criticism; Harcourt, Brace \& World: New York, NY, USA, 1958.

62. Van Etteger, R. Beyond the Visible. Prolegomenon to an Aesthetics of Designed Landscapes. Ph.D. Thesis, Wageningen University, Wageningen, The Netherlands, 2016.

63. Mean, M.; Tims, C. People Make Places: Growing the Public Life of Cities; Demos: London, UK, 2005.

64. Kincheloe, J.L. Describing the Bricolage: Conceptualizing a New Rigor in Qualitative Research. Qual. Inq. 2011, 7, 679-692. [CrossRef]

65. Simon, H.A. The Sciences of the Artificial; MIT Press: Cambridge, MA, USA, 1969.

66. Krippendorff, K. Design Research: An Oxymoron? Annenberg School for Communication, University of Pennsylvania: Philadelphia, PA, USA, 2007.

67. Cortesão, J.; Brandão, F.B.; Raaphorst, K. Photographic comparison: A method for qualitative outdoor thermal perception surveys. Int. J. Biometeorol. 2020, 64, 173-185. [CrossRef]

68. Raaphorst, K. Knowing your audience: The contingency of landscape design interpretations. J. Urban Des. 2018, 23, 654-673. [CrossRef]

69. Sheppard, S.R.J. Making climate change visible: A critical role for landscape professionals. Landsc. Urban Plan. 2015, 142, 95-105. [CrossRef]

70. McEvoy, D.; Iyer-Raniga, U.; Ho, S.; Mitchell, D.; Jegatheesan, V.; Brown, N. Integrating teaching and learning with inter-disciplinary action research in support of climate resilient urban development. Sustainability 2019, 11, 6701. [CrossRef]

(C) 2020 by the authors. Licensee MDPI, Basel, Switzerland. This article is an open access article distributed under the terms and conditions of the Creative Commons Attribution (CC BY) license (http://creativecommons.org/licenses/by/4.0/). 